\title{
CIDP Antibodies Target Junction Proteins and Identify Patient Subgroups
}

\section{An Autoantigenomic Approach}

Christian P. Moritz, Dr rer nat (PhD), * Yannick Tholance, PharmD, PhD, * Oda Stoevesandt, Dr rer nat (PhD), Karine Ferraud, CRA, Jean-Philippe Camdessanché, MD, PhD, and Jean-Christophe Antoine, MD, PhD

Neurol Neuroimmunol Neuroinflamm 2021;8:e944. doi:10.1212/NXI.0000000000000944

\author{
Correspondence \\ Dr. Moritz \\ christian.moritz@univ-st-etienne.fr
}

\begin{abstract}
\section{Objective}

To discover systemic characteristics in the repertoires of targeted autoantigens in chronic inflammatory demyelinating polyneuropathy (CIDP), we detected the entire autoantigen repertoire of patients and controls and analyzed them systematically.
\end{abstract}

\section{Methods}

We screened 43 human serum samples, of which 22 were from patients with CIDP, 12 from patients with other neuropathies, and 9 from healthy controls via HuProt Human Proteome microarrays testing about 16,000 distinct human bait proteins. Autoantigen repertoires were analyzed via bioinformatical autoantigenomic approaches: principal component analysis, analysis of the repertoire sizes in disease groups and clinical subgroups, and overrepresentation analyses using Gene Ontology and PantherDB.

\section{Results}

The autoantigen repertoires enabled the identification of a subgroup of $10 / 22$ patients with CIDP with a younger age at onset and a higher frequency of mixed motor and sensory CIDP. IV immunoglobulin therapy responders targeted 3 times more autoantigens than nonresponders. No CIDP-specific autoantibody is present in all patients; however, anchoring junction components were significantly targeted by $86.4 \%$ of patients with CIDP. There are potential novel CIDP-specific autoantigens such as the myelination- or axo-glial structure-related proteins actin-related protein $2 / 3$ complex subunit $1 \mathrm{~B}$, band 4.1 -like protein 2 , cadherin- 15 , cytohesin-1, epidermal growth factor receptor, ezrin, and radixin.

\section{Conclusions}

The repertoire of targeted autoantigens of patients with CIDP differs in a systematic degree from those of controls. Systematic autoantigenomic approaches can help to understand the disease and to discover novel bioinformatical tools and novel autoantigen panels to improve diagnosis, treatment, prognosis, or patient stratification.

\footnotetext{
*These authors contributed equally to this work and are the co-first authors.

From the Department of Neurology (C.P.M., K.F., J.-P.C., J.-C.A.), and Department of Biochemistry (Y.T.), University Hospital of Saint-Etienne; Synaptopathies and Autoantibodies (C.P.M., Y.T., J.-P.C., J.-C.A.), Institut NeuroMyoGène, INSERM U1217/CNRS UMR 5310, University of Lyon, University Jean-Monnet, Saint-Étienne, France; and Cambridge Protein Arrays Ltd. (O.S.), Babraham Research Campus, United Kingdom.

Go to Neurology.org/NN for full disclosures. Funding information is provided at the end of the article.

The Article Processing Charge was funded by the authors.
}

This is an open access article distributed under the terms of the Creative Commons Attribution-NonCommercial-NoDerivatives License 4.0 (CC BY-NC-ND), which permits downloading and sharing the work provided it is properly cited. The work cannot be changed in any way or used commercially without permission from the journal. 


\section{Glossary}

CIDP = chronic inflammatory demyelinating polyneuropathy; ENMG = electroneuromyography; FDR = false discovery rate; GO = Gene Ontology; HC = healthy control; IVIg = IV immunoglobulin; mRS = modified Rankin score; ONP = other peripheral neuropathies; $\mathbf{P C}=$ principal component; $\mathbf{P C A}$ = principal component analysis; $\mathbf{P N S}=$ peripheral nervous system; $R^{2}=$ coefficient of determination; $\mathrm{SjS}=$ Sjögren syndrome.

Chronic inflammatory demyelinating polyneuropathy (CIDP) is a rare disease of the peripheral nervous system that is considered to be immune mediated. ${ }^{1,2}$ Pathogenetic antibodies directed to proteins of the region of the node of Ranvier permit the identification of a small subgroup of patients $(<10 \%$ of CIDP) with particular features and therapeutic responses. ${ }^{3-5}$ However, in the majority of patients, no specific antibodies have been identified so far. This may be due to unsuitable identification methods or due to inappropriate hypotheses of one main antigen being targeted by the immune system. Indeed, the immune response is probably a complex process involving several antibodies and several targets with different functions in the development of the immune response and its regulation. In this case, a systemic approach may lead to a better understanding of immune-mediated diseases. ${ }^{6-9}$ Hence, recent methods aiming at identifying and understanding the entire repertoire of targeted autoantigens via autoantigenomics have been developed for the study of the immune response. ${ }^{10}$ Thus, instead of focusing on single autoantigens, this study takes an autoantigenomic approach pointing to the entire autoantigen repertoire in a systematic way via bioinformatical tools. To do so, sera from 43 subjects were tested with HuProt 3.1 Human Proteome arrays containing 15,798 human proteins expressed in yeast, representing about $75 \%$ of the gene-centric human proteome.

\section{Methods}

\section{Standard Protocol Approvals, Registrations, and Patient Consents}

The retrospective case-control and observational study involves the use of sera from human subjects, was approved by the ethical committee of the University Hospital of SaintEtienne, France, and has been performed in accordance with the Code of Ethics of the World Medical Association (the Declaration of Helsinki). All participants provided written informed consent. The privacy rights of human subjects were observed. No animal experiments were conducted for this study.

\section{Subject Selection, Description of Population, and Serum Preparation}

We collected serum samples from 22 patients with definite CIDP according to the European Federation of Neurological Societies/Peripheral Nerve Society guidelines. ${ }^{11}$

Selection criteria were the following: definite form of CIDP, ${ }^{11}$ age $\geq 18$ years, and absence of severe secondary axonal degeneration according to the electroneuromyography (ENMG). Definite CIDP was either typical (typical clinical presentation, typical ENMG data) or atypical CIDP (atypical clinical presentation, typical ENMG data). ${ }^{11,12}$ The choice of treatment was at the discretion of the neurologist who cared for the patients.

As controls, we selected roughly age and sex-matched sera samples from 12 patients with other peripheral neuropathies (ONP), 11 of whom with an associated autoimmune context-7 Sjögren syndrome (SjS), 1 autoimmune hepatitis, 1 sarcoidosis, 1 systemic lupus erythematosus, and 1 undifferentiated connective tissue disease-and 9 healthy controls (HCs) originating from the blood donation service of the French Blood Establishment in Saint-Étienne, France. All samples were selected retrospectively. Sera were prepared and stored as previously described. ${ }^{13}$

\section{Clinical Data}

For all subjects, we obtained demographic data such as age at sampling date and sex. For patients with CIDP, the following clinical data were obtained in addition: age at disease onset, course of the disease, type and topography of neurologic symptoms, type of disease's progression (chronic evolution with or without relapse or only relapses), modified Rankin scores (mRSs) during the disease course, ${ }^{14}$ ENMG data, ${ }^{15}$ biological data (CSF proteins or monoclonal gammopathy), presence of ataxia, presence of pain, concerned nerve type (sensory or motor), onset delay (acute $\leq 2$ months, subacute $=$ 2-6 months, or chronic $\geq 6$ months), ${ }^{12}$ and IV immunoglobulin (IVIg) response defined as an increase of the INCAT score by $\geq 1$ after a treatment period of 3 months. ${ }^{16}$ Because of the low number of patients treated with other immunomodulatory treatment, we did not address their response. For the comparison of IVIg responders vs nonresponders, we tested for biasing confounder effects (sampling age, delay between disease onset and sampling date, comorbidities, monoclonal gammopathy, clinical severity before treatment, and clinical presentation).

\section{Protein Microarrays and Definition of Repertoires}

Sera were tested on HuProt 3.1 Human Proteome microarrays (CDI Laboratories, Baltimore, $\mathrm{MD}$ ) as described previously. ${ }^{17}$ Most of the proteins, 14,870 (94.1\%) in numbers, are full-length proteins. The full lists of resulting groupspecific antigen repertoires were applied for the set of bioinformatical methods described below, aiming at a systemic understanding. 


\section{Principal Component Analyses}

To compare the autoantigen repertoires of CIDP and ONP + $\mathrm{HC}$, principal component analysis (PCA) was performed with the software tool from The Institute for Genomic Research, multiple experimental viewer (tigr.org/software $/ \mathrm{tm} 4 / \mathrm{mev}$. html). PCA analysis was performed with the combined sets of intra-z values of the 3 study group-specific repertoires to identify systemic differences between them and to explore the repertoire in CIDP for potential subgroups.

\section{Number of Targeted Antigens Per Subject}

For each patient, the number of targeted antigens was counted if both of the following criteria were fulfilled: (1) intra- $z$ score $\geq 2.5$ and (2) inter-z score $\geq 4$. For each study group, the corresponding other 2 study groups were used as the basis for calculating mean and SD. ${ }^{17}$

\section{Panther Analysis: Gene Ontology Overrepresentation Test}

PANTHER online software (pantherdb.org/) was applied to identify the Gene Ontology (GO) Cellular Component categories covered by the repertoires of targeted antigens (described in more detail in e-Methods, links.lww.com/NXI/ A385). In the first selection steps, we selected only categories that fulfilled all of the following categories: (1) contain $\geq 3$ targeted proteins; (2) whose number of targeted proteins is $\geq 5 \times$ higher for 1 of the 3 groups compared with the corresponding other 2 ; and (3) cover $\geq 4 \%$ of the CIDP or ONP repertoires. For the analysis based on the group-specific antigen repertoires, the percentage represents the frequency of targeted proteins set into relation with the repertoire size. Statistical analyses selected the categories that were significantly overrepresented in the CIDP repertoire compared with the $\mathrm{HC}$ repertoire.

\section{Statistics}

To show the statistical dispersion, we used the median with the 25th and 75th percentiles (abbreviated Q1-Q3 in the text) or the mean with $95 \%$ CI. For the nonparametric hypothesis tests (comparison of numbers of targeted antigens per patient), we used the Wilcoxon-Mann-Whitney test (1sided for $\mathrm{H}_{1}$ : $\mathrm{a}<\mathrm{b}$, i.e., study groups and IVIg response in the comparison of antigen numbers; 2 -sided for $\mathrm{H}_{1}$ : $\mathrm{a} \neq \mathbf{b}$, i.e., all other comparisons) via the online tool available at ccb-compute2.cs.uni-saarland.de/wtest/ (comparison performed on October 19, 2018). ${ }^{18} p$ Value $\leq 0.05$ was considered positive after Benjamini-Hochberg correction ${ }^{19}$ at level 0.05 .

For the comparison of clinical data between subgroups of patients with CIDP, we also used the Wilcoxon-MannWhitney test, and the difference of median groups was estimated by calculating the Hodges-Lehmann median with the corresponding $95 \%$ CIs.

To compare frequencies of GO categorical data, the Fisher exact test was applied via the online tool available at langsrud. com/stat/fisher.htm. ${ }^{20} p$ Value $\leq 0.05$ was considered positive after Benjamini-Hochberg correction at level 0.05. For the comparison of clinical categorial data between subgroups of patients with CIDP, we used the $\chi^{2}$ test, and the difference of frequencies with the corresponding $95 \% \mathrm{CI}$ was calculated. Correlation analysis was performed using coefficients of determination $\left(R^{2}\right)$ in Excel (version 1906; Microsoft Office ProPlus). Missing data were excluded from the analyses.

\section{Data Availability}

All anonymized data from this study or all related documents will be shared by request from any qualified investigator.

\section{Results}

\section{Patients}

Of the 22 patients with CIDP, 15 were males and 7 were females with a median age of 65.2 years $\left(Q_{1}-Q_{3}: 58.6-71.3\right)$. Thirteen patients had a chronic course, 6 had a chronic course with relapses, and 3 had a relapsing course. Twenty patients received IVIg, and 15 of 19 were considered responders (1 missing value). In 19 patients, IVIg was used alone, and 1 patient received steroids, and IVIg for 1 month followed by IVIg alone for 22 months. In this patient, response to IVIg was assessed under IVIg alone, at least 3 months after the end of steroids. Other immunomodulatory or immunosuppressive treatments were also used in 8 patients prior or after IVIg treatment (corticosteroids, azathioprine, or plasma exchanges). In 2 patients, corticosteroids were used alone. The serum sample was obtained before any treatment in 13 of 18 patients (without a significant difference between the IVIg responders and nonresponders, $p=0.17$ ). Five sera of 18 were sampled in patients who already had only 1 session of treatment in the past (pretreated); all these patients were IVIg responders (median sampling delay after the last immunomodulatory treatment: 42 days $\left(\mathrm{Q}_{1}-\mathrm{Q}_{3}: 37-79\right.$ days; extreme values: $20-450$ days).

Of the 21 control subjects ( 12 with ONP and $9 \mathrm{HC}$ ), 11 were males and 10 were females with a median age of 59.7 years $\left(\mathrm{Q}_{1}-\mathrm{Q}_{3}: 54.2-65.0\right)$.

\section{Group-Specific Repertoires of Targeted Antigens}

The selection of group-specific targeted antigens (antigens recognized only by the patients of a given group) resulted in 3 repertoires comprising $716 \mathrm{CIDP}$-specific antigens, 226 ONP-specific antigens, and $159 \mathrm{HC}$-specific antigens. Among them, 180 (25\%) CIDP-specific, 30 (13\%) ONP-specific, and 11 (7\%) HC-specific antigens were shared by at least 2 subjects. There was no significant difference between the CIDP, ONP, and HC groups regarding the mean number of antigens recognized by each subject: CIDP: 19 (CI: 13.6-24.3), ONP: 14 (CI: 10.0-17.1), and HC: 13 (CI: 7.4-18.8; figure 1A).

No antigen was specifically recognized by all patients with CIDP (i.e., not recognized by any of the control sera), and the number of patients specifically reacting with 1 shared antigen 
A. Sample group

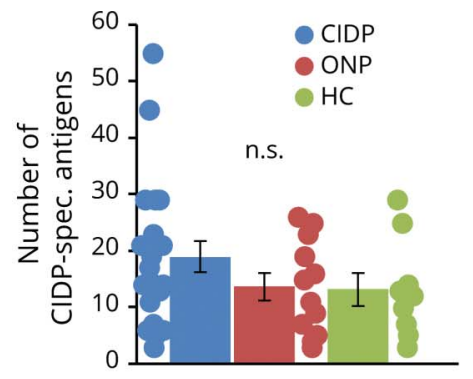

C. Pain

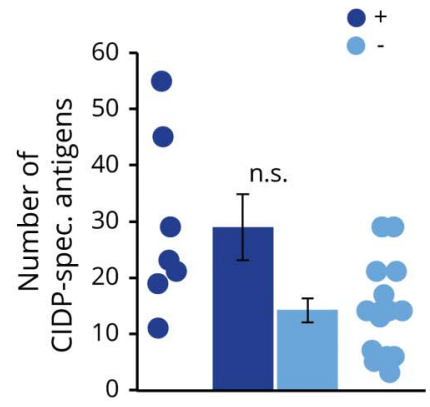

G. Axonal loss

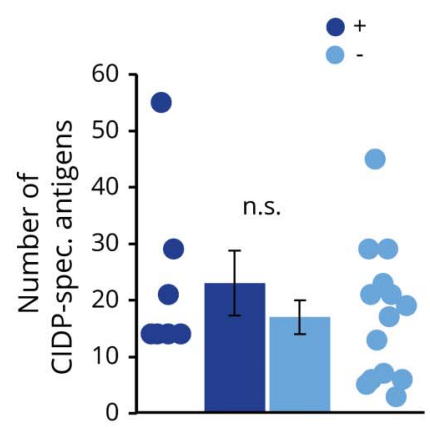

K

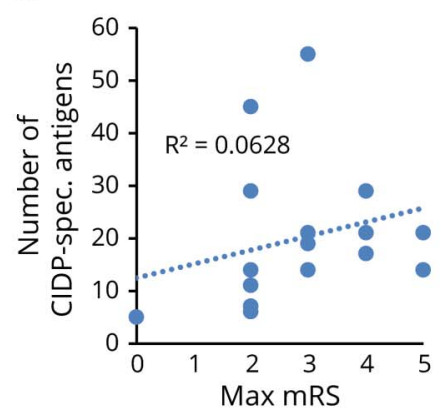

B. IVIg responder

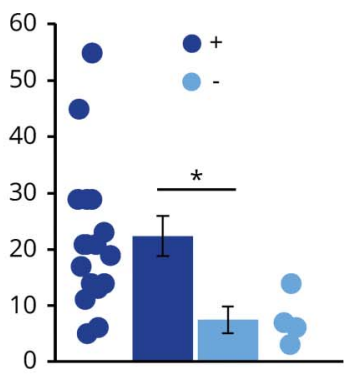

D. Conduction block

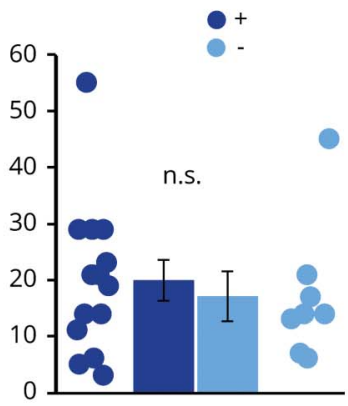

H. Ataxia

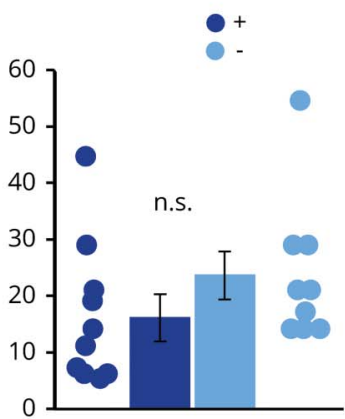

L

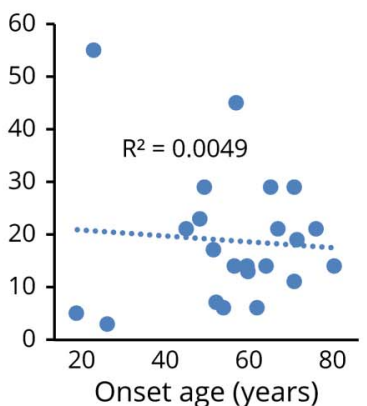

E. CIDP type

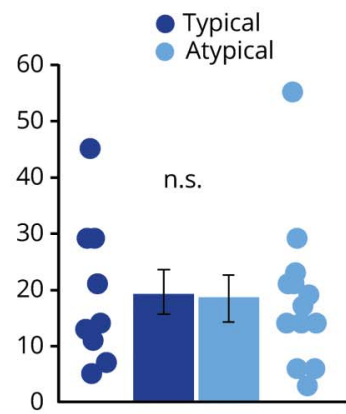

I. Symptom type

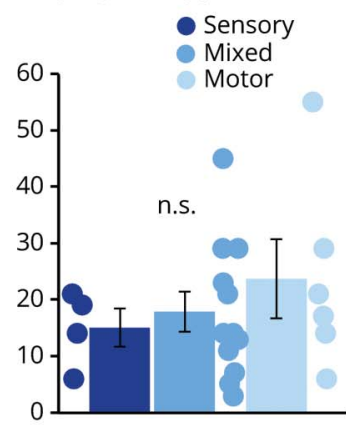

$\mathrm{M}$

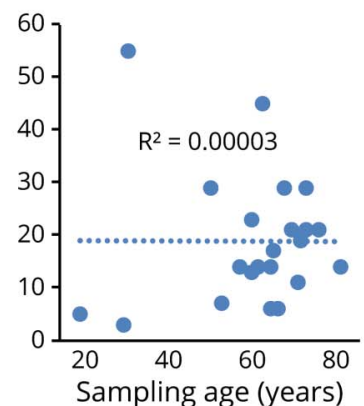

F. Sex

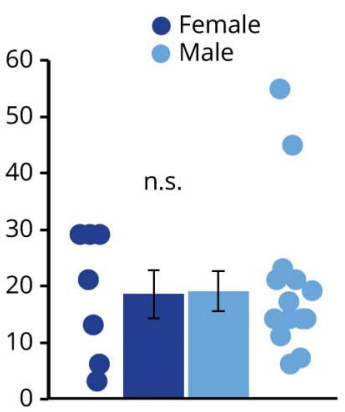

J. Onset

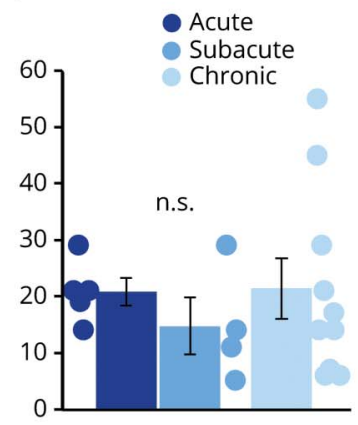

N

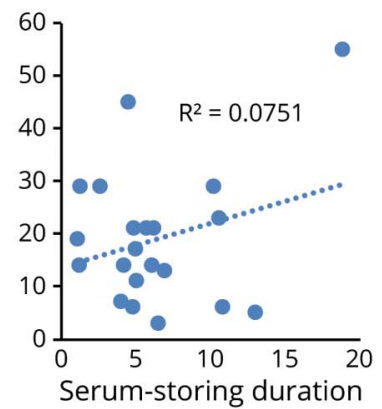

(A and B) Primary comparisons concerning the 3 sample groups (CIDP, ONP, and HC) and IVIg response among CIDP. (C-N) Comparison of further CIDP subgroups based on clinical and personal data. Spots exhibit the number of targeted antigens per subject. Bar diagram shows corresponding means of the group; error bars show SEM. * $p \leq 0.05$, Wilcoxon-Mann-Whitney test, FDR $\leq 0.05$. CIDP = chronic inflammatory demyelinating polyneuropathy; FDR = false discovery rate; $\mathrm{HC}=$ healthy control; $\max \mathrm{mRS}=$ maximal modified Rankin score; $\mathrm{ONP}=$ other peripheral neuropathies; $\mathrm{n}$.s. = not significant; $R^{2}=$ coefficient of determination.

varied from 2 to 8 . As a quality control for the HuProt 3.1 protein arrays, we used the identification by the array of wellcharacterized autoantibodies detected by routine antibodyscreening of sera for organ and non-organ-specific antibodies.
Thus, gastritis autoantibody against the plasma membrane protein $\mathrm{H}^{+} / \mathrm{K}^{+}$-ATPase in a patient with CIDP and anti-SSA1 and SSA2 antibodies in 3 patients with OND and SjS syndrome were identified by the protein array. 
The Repertoire of Targeted Antigens Identifies Subgroups of Patients With CIDP

The variation explained by the first 3 principal components (PCs) of the PCA was 23\% (PC1 $=10 \%, \mathrm{PC} 2=8 \%$, and $\mathrm{PC} 3$ $=5 \%$ ), indicating a mild general discrimination of the 3 study groups. A subgroup of 10 patients with CIDP clustered (PCA cluster 1, blue ellipse, figure 2, A and B) apart from the ONP, $\mathrm{HC}$, and the remaining 12 CIDP samples (PCA cluster 2, red ellipse, figure 2, A and B) when plotting $\mathrm{PC} 2$ and $\mathrm{PC} 3$, suggesting that these patients had a specific autoantigenome.

In the univariate model, clinical data of PCA clusters 1 and 2 were compared (table e-1, links.lww.com/NXI/A385). A younger age at onset and a higher frequency of mixed motor and sensory form of CIDP were associated with patients with CIDP of PCA cluster 1.

\section{More Antigens Targeted in IVIg Responders}

Among CIDP, the number of reactive antigens was not correlated with age at onset and sampling, sex, CIDP subtype, course, pain, ataxia, maximal $\mathrm{mRS}$, axonal loss or conduction blocks on ENMG, or serum-storing duration (figure 1, C-N).

However, we found on average 3 times more reactive antigens in IVIg responders compared with nonresponders (responders' mean: 22; CI: 15.9-28.9; nonresponders' mean: 8; CI: 2.9-12.1; $p=0.01$, false discovery rate $\leq 0.05$; figure $1 \mathrm{~B}$ ). To exclude potential confounder effects, we compared IVIg responders vs nonresponders and found no differences concerning sampling age, delay between disease onset and sampling, presence of comorbidities, monoclonal gammopathy, clinical severity before treatment, clinical presentation, and electrophysiologic data, apart from the presence of

Figure 2 PCA of Autoantigen Repertoires in CIDP and ONP + HC Groups
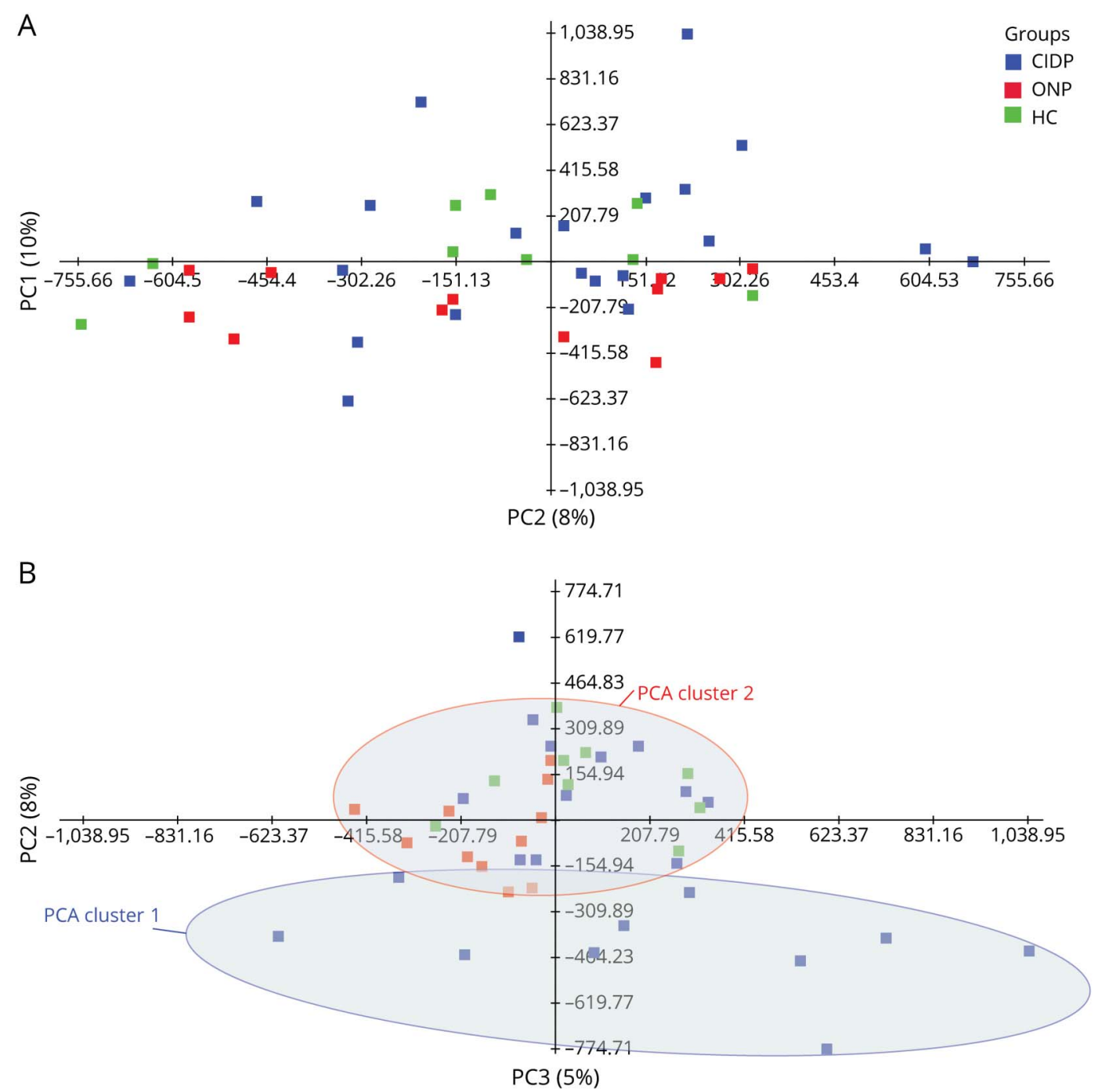

PCA in a 2D projection spanned by 2 principal components (PC) for all autoantigens for each subject of patients with CIDP (blue squares), ONP (red squares), and HC (green squares). (A) PC1 and PC2. (B) PC1 and PC3. The variation explained by the PC is indicated in parentheses. Ellipses distinguish a CIDP subgroup (cluster 1, blue ellipse) that clusters apart from ONP + HC and another CIDP subgroup that does not (cluster 2, red ellipse). CIDP = chronic inflammatory demyelinating polyneuropathy; $\mathrm{HC}$ = healthy control; ONP = other peripheral neuropathies; PCA = principal component analysis. 
A

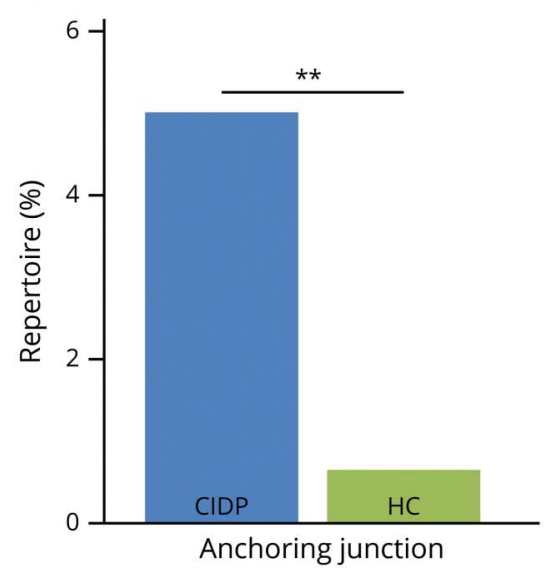

B

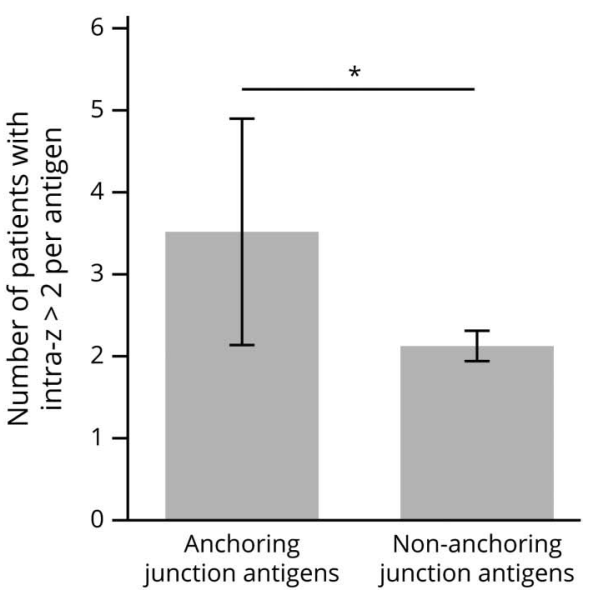

(A) Overrepresentation analyses of the antigen repertoires using the Cellular Component database of Gene Ontology via PantherDB. Percentages are calculated relative to the size of the respective antigen repertoires. ${ }^{* *} p \leq 0.01$, Fisher exact test. (B) Mean number of reactive patients (intra-z $>2$ ) per antigen. *Exclusion of 0 by the confident interval of the mean difference $(1.4 ; \mathrm{Cl}$ : $0.002-2.8)$; error bars: $95 \% \mathrm{Cl}$. conduction blocks, which was more frequent in IVIg responders compared with nonresponders (table e-2, links.lww. com/NXI/A385). The presence of the 5 pretreated patients in the group of IVIg responders was not a confounding factor as there was no significant difference regarding the numbers of targeted antigens between the IVIg-naive and pretreated patients (20 [CI: $13.2-26.7$ ] vs 15 [CI: 10.3-20.5]; $p=0.31$ ), showing that the 5 pretreated patients did not influence the significant difference of the number of targeted antigens between IVIg responders and nonresponders.

\section{Anchoring Junction Proteins Were Significantly Targeted by Sera of Patients With CIDP}

Two hundred seventy-five (38.4\%) antigens among the CIDP repertoire, 79 (35.0\%) antigens among the ONP repertoire, and 61 (38.4\%) antigens among the HC repertoire were annotated to at least one of the cellular components, "Plasma membrane" and/or "Extracellular space" according to GO.

The overrepresentation analysis of cellular components with the Panther algorithm showed that the category "anchoring junction" was significantly overrepresented in the CIDP repertoire compared with the $\mathrm{HC}$ repertoire (figure $3 \mathrm{~A}$ ). Nineteen of 22 patients with CIDP (86.4\%) had antibodies against at least one of these proteins. In average, each of the detected anchoring junction proteins was targeted by 3.6 (CI: 2.2-5.0) patients with CIDP, which is significantly more than for each of the rest of CIDP-specific non-junction proteins being targeted by an average of 2.2 patients each (CI: 2.0-2.3; difference of mean 1.4 [CI 0.002-2.8]; figure 3B). Twentyone of $35(60.0 \%)$ targeted anchoring junction proteins were annotated to the cellular components "Plasma membrane" $(15 / 35,42.9 \%)$ and/or "Extracellular region or secreted" (16/35, 45.7\%) according to GO and are listed in table 1 . Although expressed in a wide range of organs, most of them $(19 / 21)$ are known to play roles in the nervous system or even more specifically in the peripheral nervous system $(13 / 21)$. Seven of them are known to play roles in myelination or in the organization or maintenance of axo-glial structures (actinrelated protein $2 / 3$ complex subunit $1 \mathrm{~B}$, band 4 .1-like protein 2 , cadherin-15, cytohesin-1, epidermal growth factor receptor, ezrin, and radixin). Each of the CIDP-specific anchoring junction protein was targeted by $1-6$ patients, and each patient reacted with $0-14$ of junction proteins.

\section{Discussion}

Autoantigenomics provides the opportunity to mine systemic comprehension from autoantibody repertoires. ${ }^{10}$ Using bioinformatical tools known from proteomics, ${ }^{21,22}$ this method seeks to discover significant patterns in the repertoire of targeted autoantigens. In other words, instead of the classical approach of searching 1 single autoantibody and defining the vast rest as noise, autoantigenomics is focusing on related sets of autoantigen groups that emerge from the data set. In this study, we implemented this systemic mining for $716 \mathrm{CIDP}$-specific antigens, resulting from a quasi-proteome-wide screening of 22 patients with definite CIDP. Although seemingly low, our sample sizes are in the same range as those of similar protein microarray studies. ${ }^{23-25}$

Our approach resulted in the following main conclusions. On a systematic level, (1) the recognized repertoire of targeted antigens enables the identification of patient subgroups with differing clinical patterns and responses to IVIg; (2) anchoring junction proteins are a significant target of the CIDPspecific antibody repertoire; and (3) on a single antigen level, our approach revealed several novel interesting autoantigens that could be embarked on by the community.

The antigen repertoire specific to CIDP identified in this study contains hundreds of proteins of which only $25 \%$ were recognized 
Table 1 Anchoring Junction Proteins Associated With the Plasma Membrane or Extracellular Space

\begin{tabular}{|c|c|c|}
\hline Protein name & Known role in the nervous system & $\begin{array}{l}\text { Impact on actin } \\
\text { cytoskeleton }\end{array}$ \\
\hline 14-3-3 protein zeta/delta & Regulates spine maturation & - \\
\hline Actin-related protein 2/3 complex subunit 1B & $\begin{array}{l}\text { Process extension and axon ensheathment during myelination; in PNS: actin } \\
\text { cytoskeleton regulation of DRG growth cones }\end{array}$ & + \\
\hline Annexin A6 & $\begin{array}{l}\text { In PNS: scaffolding protein during membrane biogenesis and } \mathrm{Ca}^{2+} \text { conductance } \\
\text { modulation in sensory neurons }\end{array}$ & + \\
\hline Band 4.1-like protein 2 & In PNS: axo-glial organization and maintenance in myelinated axons & + \\
\hline $\begin{array}{l}\text { Brain-specific angiogenesis inhibitor 1- } \\
\text { associated protein } 2\end{array}$ & Filopodia formation; dendritic branch formation; synaptic transmission & + \\
\hline $\begin{array}{l}\text { Brain-specific angiogenesis inhibitor 1- } \\
\text { associated protein 2-like protein } 1\end{array}$ & In PNS: biomarker for mechanical nociceptor type of DRG neurons & + \\
\hline Cadherin-15 & $\begin{array}{l}\text { In PNS: potential roles in axon/Schwann cell interactions and node of Ranvier } \\
\text { structural maintenance }\end{array}$ & - \\
\hline CD59 glycoprotein & $\begin{array}{l}\text { Protecting from autoimmune neurologic disease and neural lesions; in PNS: } \\
\text { deficiency can present as CIDP }\end{array}$ & - \\
\hline Cdc42 effector protein 4 & Scaffold protein contributing to glia-neuron configuration & + \\
\hline Cell surface glycoprotein MUC18 & Role in neuroinflammation; neurite extension & + \\
\hline Copine-3 & - & - \\
\hline Coronin-1B & - & + \\
\hline Cytohesin-1 & In PNS: regulation of myelination & + \\
\hline E3 ubiquitin-protein ligase CBL & Role in microglia-mediated neuroinflammation; neuroprotective role & + \\
\hline Epidermal growth factor receptor & $\begin{array}{l}\text { Regulation of myelination via oligodendrocyte' maturation; astrocyte } \\
\text { differentiation and maturation. In PNS: regulation of neurite outgrowth, } \\
\text { nociception }\end{array}$ & + \\
\hline Ezrin & $\begin{array}{l}\text { In PNS: node of Ranvier formation; concentrated at node of Ranvier and colocalizes } \\
\text { with NF155 }\end{array}$ & + \\
\hline $\begin{array}{l}\text { Membrane-associated guanylate kinase, WW } \\
\text { and PDZ domain-containing protein } 1\end{array}$ & $\begin{array}{l}\text { In PNS: scaffolding for ion transport in DRG neurons; role in thermal nociception } \\
\text { and acute inflammatory pain }\end{array}$ & + \\
\hline Poly(rC)-binding protein 2 & $\begin{array}{l}\text { Neuronal cell proliferation and apoptosis; in PNS: Schwann cell proliferation after } \\
\text { nerve injury }\end{array}$ & - \\
\hline Protein disulfide-isomerase $\mathrm{A} 3$ & Neuroprotective role; in PNS: supporting peripheral nerve regeneration & - \\
\hline Radixin & Neuroblast proliferation and migration; in PNS: node of Ranvier formation & + \\
\hline Transducin-like enhancer protein 2 & Regulation of neuronal differentiation & - \\
\hline
\end{tabular}

Abbreviations: CIDP = chronic inflammatory demyelinating polyneuropathy; DRG = dorsal root ganglia; PNS = peripheral nervous system. Categories according to Gene Ontology. Literature references in e-Methods, links.Iww.com/NXI/A385.

by several patients, showing that the greater part of the antibody response is individual and fingerprint-like. ${ }^{26}$ We found no specific antigen recognized by all the patients but groups of antigens that are targeted by several patients. This suggests that there is low chance of identifying 1 biomarker antibody for typical CIDP, even if the panel of antigens used in the study does not cover the totality, but only $75 \%$ of the human proteome, leaving open the possibility that this particular antigen is by chance in the missing part of the antigenome or spotted in a nonreactive conformation.

Instead, we found a complex antibody response. Of interest, this global antibody response was not produced haphazardly as it is correlated with different clinical aspects of the CIDP. Thus, using the CIDP-specific antigenome, PCA identified a cluster of $10 / 22(45 \%)$ deviant patients who were younger at disease onset and more often had a mixed motor and sensory form of CIDP. Furthermore, patients who were IVIg responders targeted on average 3 times more antigens than IVIg nonresponders, and this was an independent effect. All these results, and especially those concerning the response to IVIg, were obtained with a low number of patients and need to be confirmed on a larger series. However, they are in keeping with the fact that CIDP is a heterogenous entity ${ }^{27}$ and that response to IVIg in this disease probably depends on complex 
immunologic factors specific to subgroups of patients. ${ }^{28}$ The identification of these subgroups may be helpful for treatment management and patient stratification in clinical trials.

An interesting finding is that anchoring junction proteins, although in a numerical minority in the human antigenome, are overrepresented in the repertoire of targeted antigens of CIDP. This was a general phenomenon since $86.4 \%$ of the patients with CIDP had antibodies against at least one of these proteins. The fact that each identified anchoring junction protein was on average targeted by significantly more patients with CIDP than all other CIDP-specific antigens also suggests that this is not an incidental antigen set. Anchoring junction proteins are important for maintaining the neuronal-glial cell shapes. Most of our detected anchoring junction proteins $(14 / 21)$ interfere in some way with the actin cytoskeleton; 7 are known to play a role in the myelination or axo-glial structuring process (table 1). In addition, given their roles or locations in the peripheral nervous system, 3 of these proteins (CD59 glycoprotein, Ezrin, and Radixin) have previously been discussed as potential targets for autoantibodies in demyelinating neuropathies. $^{29,30}$

Other junction ${ }^{31-33}$ or cell adhesion ${ }^{34-37}$ proteins of the nodal and paranodal region including contactin-1 and neurofascin 155 and 186 have been identified as antibody targets in subgroups of CIDP, confirming that these protein groups comprise important autoantigens in CIDP. However, in contrast to the predominantly neural proteins contactin-1 and neurofascin 155 and 186, the proteins identified in our study are-despite their roles in the nervous system - mostly widely expressed. Contactin-1 and neurofascin 155 and 186 are not on the HuProt 3.1 array. None of the 7 node of Ranvier proteins spotted on the arrays were targeted by the patients' sera. Thus, proteins specific to the node of Ranvier are probably not the main targets of antibodies in CIDP as a whole but only in a subgroup of patients who had a specific form of CIDP or even form another disease entity (e.g., [para-]nodopathy). ${ }^{38}$

Because of the low number of only 3 anti-junction proteinnegative patients, it was not possible to determine whether a specific clinical pattern is associated with the targeting of these proteins. Antibodies reacting with the nodal and paranodal regions are probably causally involved in the lesioning process by interfering with their target. ${ }^{5,39,40}$ Whether this is the case with the antibodies identified in this study is not yet determined. Although the complex specific antibody response is linked with clinical characteristics of the CIDP, it is not possible to know whether it contributes to the lesioning process or is a secondary phenomenon or a mixture of both. Regarding a diagnostic potential, each of the antibodies identifies a restricted proportion of patients, as do the known antibodies reacting with the node of Ranvier. However, several of them, alone or in combination, may be candidate biomarkers for the diagnosis of CIDP or for managing the treatment by IVIg.
In conclusion, this article describes the application of autoantigenomics, i.e., the systematic analysis of the whole autoantigen repertoire, in the neurology field. The identified candidates present novel potential antibody targets of CIDP that could be embarked on-either as single antigens or panels - by the community. The discovered set of antibodies against anchoring junction proteins may be of interest for diagnostics, prognosis, and patient stratification. At the same time, the research community interested in not only CIDP but also other inflammatory neuropathies might broaden their view from single candidates to a more systemic view of antigen repertoires. Functional or compartmental sets of targeted antigens suggest novel, more systematic tools to diagnose and understand autoimmune neuropathies.

\section{Acknowledgment}

The authors thank Michael J. Taussig for hosting C.P.M. in his labs and for helpful discussions, Claudia Fonseca for technical assistance and teaching the handling with HuProt Human Proteome microarrays, Carole Rosier for contributing to diagnosing patients with CIDP, Evelyne Reynaud-Federspiel for helping with logistics regarding storage and sending of sera, Jérôme Honnorat for helpful discussions, Priyanka Garg for proofreading an earlier version of the manuscript, and all anonymous patients and donors for their contribution to this study. Some authors are members of the ERN Euro-NMD.

\section{Study Funding}

The study was funded, but not the article. University Hospital of Saint-Etienne; German Research Foundation (DFG; MO 3240/1-1:1); Association Française contre les Myopathies (AFM-MyoNeurALP project 6.1.1); BETPSY project, Investissements d'Avenir program of the French National Research Agency (ANR, reference ANR-18-RHUS-0012); and Fonds de dotation CSL Behring pour la recherche.

\section{Disclosure}

C.P. Moritz received travel grants from CSL Behring (France), outside the submitted work. Y. Tholance reports personal fees from The Binding Site and Alexion, outside the submitted work. O. Stoevesandt was an employee of Cambridge Protein Arrays Ltd. K. Ferraud declares no competing interests. J.-P. Camdessanché reports personal fees for lectures, consulting, writing of articles, or training courses from Akcea, Alnylam, Biogen, CSL Behring, Genzyme, Laboratoire Français des Biotechnologies (LFB), Merck, Novartis, Pfizer, Pharmalliance, Teva, Editions Scientifiques L\&C, Edimark, Expression Santé, Natus, Scien, and SNF-Floerger, outside the submitted work, and is holding a patent on anti-FGFR3 autoantibodies. J.-C. Antoine received honoraria for scientific counseling from Pfizer and from a license on diagnostic test for the detection of anti-CRMP5 antibodies and travel grants from LFB, outside the submitted work, and is holding a patent on anti-FGFR3 autoantibodies. Go to Neurology.org/NN for full disclosures. 


\section{Publication History}

Received by Neurology: Neuroimmunology \& Neuroinflammation April 11, 2020. Accepted in final form October 29, 2020.

Appendix Authors

\begin{tabular}{|c|c|c|}
\hline Name & Location & Contribution \\
\hline $\begin{array}{l}\text { Christian P. } \\
\text { Moritz, Dr rer } \\
\text { nat (PhD) }\end{array}$ & $\begin{array}{l}\text { Synaptopathies and } \\
\text { Autoantibodies, Institut } \\
\text { NeuroMyoGene, Saint- } \\
\text { Etienne, France }\end{array}$ & $\begin{array}{l}\text { Designed and } \\
\text { conceptualized the } \\
\text { study, acquisition of } \\
\text { data, analyzed the data, } \\
\text { and drafted and revised } \\
\text { the manuscript for } \\
\text { intellectual content }\end{array}$ \\
\hline
\end{tabular}

\begin{tabular}{ll}
\hline Yannick & Department of \\
Tholance, & Biochemistry, University \\
PharmD, PhD & Hospital of Saint-Etienne, \\
& France
\end{tabular}

Acquisition of data, analyzed the data, and drafted and revised the manuscript for intellectual content

\begin{tabular}{ll}
\hline Oda & Cambridge Protein \\
Stoevesandt, Dr & Arrays Ltd., Babraham \\
rer nat (PhD) & Research Campus, \\
& United Kingdom
\end{tabular}

Designed and conceptualized the study, acquisition of data, analyzed the data, and revised the manuscript for intellectual content

\begin{tabular}{lll}
\hline $\begin{array}{l}\text { Karine Ferraud, } \\
\text { CRA }\end{array}$ & $\begin{array}{l}\text { Department of } \\
\text { Neurology, University } \\
\text { Hospital of Saint-Etienne, } \\
\text { France }\end{array}$ & $\begin{array}{l}\text { Acquisition of data and } \\
\text { revised the manuscript } \\
\text { for intellectual content }\end{array}$ \\
\hline $\begin{array}{l}\text { Jean-Philippe } \\
\text { Camdessanché, } \\
\text { MD, PhD }\end{array}$ & $\begin{array}{l}\text { Department of } \\
\text { Neurology, University } \\
\text { Hospital of Saint-Etienne, } \\
\text { France }\end{array}$ & $\begin{array}{l}\text { Contributed to study } \\
\text { design and concept, } \\
\text { patient inclusion, } \\
\text { interpreted the data, and } \\
\text { revised the manuscript } \\
\text { for intellectual content }\end{array}$ \\
\hline $\begin{array}{l}\text { Jean-Christophe } \\
\text { Antoine, MD, }\end{array}$ & $\begin{array}{l}\text { Department of } \\
\text { PhD }\end{array}$ & $\begin{array}{l}\text { Designed and } \\
\text { conceptualized the } \\
\text { Hospital of Saint-Etienne, }\end{array}$ \\
& France & $\begin{array}{l}\text { study, study coordinator, } \\
\text { patient inclusion, } \\
\text { acquisition of data, and } \\
\text { revised the manuscript } \\
\text { for intellectual content }\end{array}$ \\
\hline & & \\
\hline
\end{tabular}

\section{References}

1. Rodríguez Y, Vatti N, Ramírez-Santana C, et al. Chronic inflammatory demyelinating polyneuropathy as an autoimmune disease. J Autoimmun 2019;102:8-37.

2. Rajabally YA, Attarian S, Delmont E. Evolving immunologic perspectives in chronic inflammatory demyelinating polyneuropathy. J Inflamm Res 2020;13:543-549.

3. Querol L, Devaux J, Rojas-Garcia R, Illa I. Autoantibodies in chronic inflammatory neuropathies: diagnostic and therapeutic implications. Nat Rev Neurol 2017;13:533-547.

4. Pascual-Goñi E, Martín-Aguilar L, Querol L. Autoantibodies in chronic inflammatory demyelinating polyradiculoneuropathy. Curr Opin Neurol 2019;32:651-657.

5. Cortese A, Lombardi R, Briani C, et al. Antibodies to neurofascin, contactin-1, and contactin-associated protein 1 in CIDP: clinical relevance of IgG isotype. Neurol Neuroimmunol Neuroinflamm 2020;7:e639.

6. Meyer S, Woodward M, Hertel C, et al. AIRE-deficient patients harbor unique highaffinity disease-ameliorating autoantibodies. Cell 2016;166:582-595.

7. Alter G, Dowell KG, Brown EP, et al. High-resolution definition of humoral immune response correlates of effective immunity against HIV. Mol Syst Biol 2018;14:e7881.

8. Lewis MJ, McAndrew MB, Wheeler C, et al. Autoantibodies targeting TLR and SMAD pathways define new subgroups in systemic lupus erythematosus. J Autoimmun 2018; 91:1-12.

9. Boligan KF, Oechtering J, Keller CW, et al. Xenogeneic Neu5Gc and self-glycan Neu5Ac epitopes are potential immune targets in MS. Neurol Neuroimmunol Neuroinflamm 2020;7:e676.

10. Moritz CP, Paul S, Stoevesandt O, Tholance Y, Camdessanché JP, Antoine JC. Autoantigenomics: holistic characterization of autoantigen repertoires for a better understanding of autoimmune diseases. Autoimmun Rev 2020;19:102450.
11. Joint Task Force of the EFNS and the PNS. European Federation of Neurological Societies/Peripheral Nerve Society guideline on management of chronic inflammatory demyelinating polyradiculoneuropathy: report of a joint task force of the European Federation of Neurological Societies and the Peripheral Nerve Societyfirst revision. J Peripher Nerv Syst 2010;15:1-9.

12. French CIDP Study Group; Vallat JM. Recommendations on diagnostic strategies for chronic inflammatory demyelinating polyradiculoneuropathy. Postgrad Med J 2008; 84:378-381.

13. Moritz CP, Tholance Y, Lassablière F, Camdessanché JP, Antoine JC. Reducing the risk of misdiagnosis of indirect ELISA by normalizing serum-specific background noise: the example of detecting anti-FGFR3 autoantibodies. J Immunol Methods $2019 ; 466: 52-56$.

14. van Swieten JC, Koudstaal PJ, Visser MC, Schouten HJ, van Gijn J. Interobserver agreement for the assessment of handicap in stroke patients. Stroke 1988;19:604-607.

15. Camdessanché JP, Antoine JC, Honnorat J, et al. Paraneoplastic peripheral neuropathy associated with anti-Hu antibodies. A clinical and electrophysiological study of 20 patients. Brain 2002;125:166-175.

16. Hughes $\mathrm{R}$, Bensa S, Willison $\mathrm{H}$, et al. Randomized controlled trial of intravenous immunoglobulin versus oral prednisolone in chronic inflammatory demyelinating polyradiculoneuropathy. Ann Neurol 2001;50:195-201.

17. Moritz CP, Stoevesandt O, Tholance Y, Camdessanché JP, Antoine JC. Proper definition of the set of autoantibody-targeted antigens relies on appropriate reference group selection. N Biotechnol 2020;60:168-172.

18. Marx A, Backes C, Meese E, Lenhof HP, Keller A. EDISON-WMW: exact dynamic programing solution of the Wilcoxon-Mann-Whitney test. Genomics Proteomics Bioinformatics 2016;14:55-61.

19. Benjamini $Y$, Hochberg Y. Controlling the false discovery rate: a practical and powerful approach to multiple testing. J R Stat Soc Ser B 1995;57:289-300.

20. Agresti A. A survey of exact inference for contingency tables. Stat Sci 1992;7:131-153.

21. Moritz CP, Eckstein E, Tenzer S, Friauf E. Neuroproteomics in the auditory brainstem: candidate proteins for ultrafast and precise information processing. Mol Cell Neurosci 2015;64:9-23.

22. Kumar C, Mann M. Bioinformatics analysis of mass spectrometry-based proteomics data sets. FEBS Lett 2009;583:1703-1712.

23. Heming M, Schulte-Mecklenbeck A, Brix T, et al. Immune cell profiling of the cerebrospinal fluid provides pathogenetic insights into inflammatory neuropathies. Front Immunol 2019;10:515.

24. Sim KY, Park SH, Choi KY, et al. High-throughput epitope profiling of antibodies in the plasma of Alzheimer's disease patients using random peptide microarrays. Sci Rep 2019;9:4587.

25. Chung BK, Guevel BT, Reynolds GM, et al. Phenotyping and auto-antibody production by liver-infiltrating $B$ cells in primary sclerosing cholangitis and primary biliary cholangitis. J Autoimmun 2017;77:45-54.

26. Moritz CP, Tholance Y, Rosier C, et al. Completing the immunological fingerprint by refractory proteins: autoantibody screening via an improved immunoblotting technique. Proteomics Clin Appl 2019;13:e1800157.

27. Bunschoten C, Eftimov F, van der Pol WL, Jacobs BC; ICOS Consortium. International chronic inflammatory demyelinating polyneuropathy outcome study (ICOS): protocol of a prospective observational cohort study on clinical and biological predictors of disease course and outcome. J Peripher Nerv Syst 2019;24: 34-38.

28. Galeotti C, Kaveri SV, Bayry J. IVIG-mediated effector functions in autoimmune and inflammatory diseases. Int Immunol 2017;29:491-498.

29. Miyaji K, Shahrizaila N, Umapathi T, Chan YC, Hirata K, Yuki N. Are ERM (ezrin/ radixin/moesin) proteins targets for autoantibodies in demyelinating neuropathies? Hum Immunol 2014;75:1089-1091.

30. Miyaji K, Paul F, Shahrizaila N, Umapathi T, Yuki N. Complement regulatory proteins (CD46, 55 and 59) expressed on Schwann cells: immune targets in demyelinating neuropathies? J Neuroimmunol 2014;276:172-174.

31. Stathopoulos P, Alexopoulos H, Dalakas MC. Autoimmune antigenic targets at the node of Ranvier in demyelinating disorders. Nat Rev Neurol 2015;11:143-156.

32. Mathey EK, Garg N, Park SB, et al. Autoantibody responses to nodal and paranodal antigens in chronic inflammatory neuropathies. J Neuroimmunol 2017;309:41-46.

33. Delmont E, Brodovitch A, Kouton L, et al. Antibodies against the node of Ranvier: a real-life evaluation of incidence, clinical features and response to treatment based on a prospective analysis of 1500 sera. J Neurol 2020;267:3664-3672.

34. $\mathrm{Ng} \mathrm{JKM,} \mathrm{Malotka} \mathrm{J,} \mathrm{Kawakami} \mathrm{N,} \mathrm{et} \mathrm{al.} \mathrm{Neurofascin} \mathrm{as} \mathrm{a} \mathrm{target} \mathrm{for} \mathrm{autoantibodies} \mathrm{in}$ peripheral neuropathies. Neurology 2012;79:2241-2248.

35. Querol L, Illa I. Paranodal and other autoantibodies in chronic inflammatory neuropathies. Curr Opin Neurol 2015;28:474-479.

36. Devaux JJ, Miura Y, Fukami Y, et al. Neurofascin-155 IgG4 in chronic inflammatory demyelinating polyneuropathy. Neurology 2016;86:800-807.

37. Martinez-Martinez L, Lleixà MC, Boera-Carnicero G, et al. Anti-NF155 chronic inflammatory demyelinating polyradiculoneuropathy strongly associates to HLADRB15. J Neuroinflammation 2017;14:224.

38. Tang L, Huang Q, Qin Z, Tang X. Distinguish CIDP with autoantibody from that without autoantibody: pathogenesis, histopathology, and clinical features. J Neurol Epub 2020 Apr 7.

39. Manso C, Querol L, Mekaouche M, Illa I, Devaux JJ. Contactin-1 IgG4 antibodies cause paranode dismantling and conduction defects. Brain 2016;139:1700-1712.

40. Manso $\mathrm{C}$, Querol L, Lleixà $\mathrm{C}$, et al. Anti-neurofascin-155 IgG4 antibodies prevent paranodal complex formation in vivo. J Clin Invest 2019;129:2222-2236. 


\section{Neurology ${ }^{\oplus}$ \\ Neuroimmunology \& Neuroinflammation}

CIDP Antibodies Target Junction Proteins and Identify Patient Subgroups: An Autoantigenomic Approach

Christian P. Moritz, Yannick Tholance, Oda Stoevesandt, et al.

Neurol Neuroimmunol Neuroinflamm 2021;8;

DOI 10.1212/NXI.0000000000000944

This information is current as of January 6, 2021

Neurol Neuroimmunol Neuroinflamm is an official journal of the American Academy of Neurology.

Published since April 2014, it is an open-access, online-only, continuous publication journal. Copyright

Copyright $\odot 2021$ The Author(s). Published by Wolters Kluwer Health, Inc. on behalf of the American

Academy of Neurology.. All rights reserved. Online ISSN: 2332-7812.

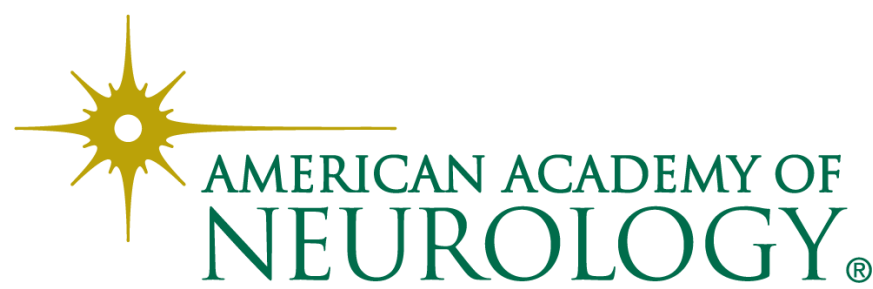




\section{Updated Information \& Services}

References

Citations

Subspecialty Collections

Permissions \& Licensing

Reprints including high resolution figures, can be found at: http://nn.neurology.org/content/8/2/e944.full.html

This article cites 39 articles, 4 of which you can access for free at: http://nn.neurology.org/content/8/2/e944.full.html\#\#ref-list-1

This article has been cited by 1 HighWire-hosted articles: http://nn.neurology.org/content/8/2/e944.full.html\#\#otherarticles

This article, along with others on similar topics, appears in the following collection(s):

All Immunology

http://nn.neurology.org//cgi/collection/all_immunology

Autoimmune diseases

http://nn.neurology.org//cgi/collection/autoimmune_diseases

Chronic inflammatory demyelinating polyneuropathy

http://nn.neurology.org//cgi/collection/chronic_inflammatory_demyeli nating_polyneuropathy

Peripheral neuropathy

http://nn.neurology.org//cgi/collection/peripheral_neuropathy

Information about reproducing this article in parts (figures,tables) or in its entirety can be found online at:

http://nn.neurology.org/misc/about.xhtml\#permissions

Information about ordering reprints can be found online: http://nn.neurology.org/misc/addir.xhtml\#reprintsus

Neurol Neuroimmunol Neuroinflamm is an official journal of the American Academy of Neurology.

Published since April 2014, it is an open-access, online-only, continuous publication journal. Copyright

Copyright $\odot 2021$ The Author(s). Published by Wolters Kluwer Health, Inc. on behalf of the American

Academy of Neurology.. All rights reserved. Online ISSN: 2332-7812.

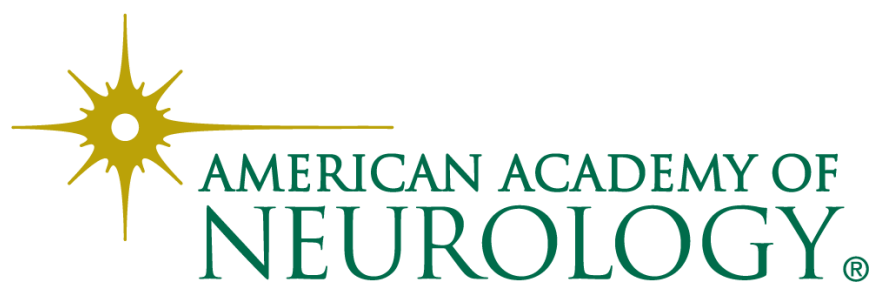

